\title{
Difficulties and Strategies in the Process of Population Urbanization: A Case Study in Chongqing of China
}

\author{
Lin Lu, Yin Zhang, Tingting Luo \\ Culture and Social Development Study School, Southwest University, Chongqing, China \\ Email: lulin@swu.edu.cn, zhy@swu.edu.cn
}

Received 24 October 2014; revised 24 november 2014; accepted 1 December 2014

Copyright () 2014 by authors and Scientific Research Publishing Inc.

This work is licensed under the Creative Commons Attribution International License (CC BY).

http://creativecommons.org/licenses/by/4.0/

(c) (i) Open Access

\begin{abstract}
The population urbanization is one of the main routes and objectives of current Chinese urbanization. This paper, a case study in Chongqing, China, based on statistical data analysis and the forecasting of population growth trend, combined with the development law of population urbanization and regional reality, mainly discusses major problems facing the development of China's population urbanization, economic, social and institutional obstacles to the solution of these problems in the development of population urbanization, and effective ways to promote positive interactions between the population urbanization and the economy, society and space. The analysis reveals that in the process of the population urbanization, due to the large population base, large agricultural population, serious population aging problem and low level of education of population, China's population urbanization development does not match with economic and social development in objective and pattern; there is a glaring contradiction in industrial upgrading, labor supply, the population migration and relocation. It is necessary to take corresponding strategies in the population urbanization, population management system, labor resources and elderly-care policies, human resource development and economic growth, surplus agricultural population migration and the urban-and-rural development, in order to solve these contradictions and find out real effective ways to achieve positive interaction between the population urbanization and the economic and social development.
\end{abstract}

\section{Keywords}

Population Urbanization, Population Quality, Migration, Local Integration and Aging Population

\section{Introduction}

Urbanization has become an important feature and direction of the new stage of development in China today. At

How to cite this paper: Lu, L., Zhang, Y. and Luo, T.T. (2014) Difficulties and Strategies in the Process of Population Urbanization: A Case Study in Chongqing of China. Open Journal of Social Sciences, 2, 90-95. 
of the end of 2013, China's urbanization rate reached 53.7 percent. According to the theory of urbanization development stage, China's urbanization development has entered the second stage, namely the steady growth stage. It is put forward that in new stage in order to develop urbanization we should replace the old "extensive" and "out-of-order" development pattern [1]. The core of new urbanization is the population urbanization. "The core of the new urbanization is the urbanization of the people" (Keqiang Li, 2014). Therefore, to solve the problem of population urbanization is an important mode and approach to promote economic development, social harmony, and the balance relationship between man and nature. As the only municipality in western China, one of five national central cities and a national "pilot site for overall urban-and-rural reform", Chongqing has a prominent position in the western development and the construction of new urbanization. Its development path has a representative significance to some extent. Since Chongqing became a municipality, the population urbanization has made steady and rapid growth; however, there have been some contradictions and difficulties incompatible with new urbanization development. This paper, from the characteristics of the population urbanization of Chongqing, analyzes and concludes some manifestations and reasons of population urbanization not suitable with regional development in Chongqing, and tries to find a way for the population urbanization in line with regional specialties of western China [2].

\section{The Characteristics of Population Urbanization and Its Impact}

\subsection{The Characteristics of Population Urbanization in Chongqing}

First, Chongqing has a large population base and a large agricultural population. Chongqing resident population urbanization rate increased from 35.6 percent in 2000 to 55.0 percent in 2011, with an increase of nearly 20 percent and an average annual growth of about 1.76 percent. However, in the four municipalities in China, Chongqing has the largest population, but its urbanization rate of the resident population is the minimum. According to the sixth nationwide census data (in 2010), Chongqing has a gross resident population of 28.846 million, of which the urban population is 15.2955 million; the urbanization rate is 53.02 percent. The total population is much higher than that of other municipalities in same period, but the urbanization rate is far lower (Table 1). It is thus clear that Chongqing has a large population base and a large agricultural population. Compared with other municipalities, the urbanization of Chongqing has a long way to go [3]-[5].

Second, Chongqing has the problems of the population aging and the low level of labor quality. Chongqing's population aging degree is relatively high and its population education degree is relatively low. According to data of "Sixth Census", Chongqing aging population accounted for 11.6 percent of the total population, the population graduated from university (college and above) for 8.6 percent of the total population, the illiterate population, with a number of 1.239 million, for 4.3 percent of the total population by that year. It can be seen that, compared with other provinces (cities, districts) in the same period, Chongqing's population aging degree is the highest and the education level of the population is relatively low. Data, to some extent, reflect the population structure of Chongqing and the condition of labor quality, thus it can be inferred that the quality of population urbanization of Chongqing is not high.

\subsection{The Influence of Population Urbanization on the Development of Chongqing}

Chongqing's population urbanization quality has brought some obstacles to local economic and social development, and does not match the local economic and social development, in particular in two ways:

Table 1. Comparison table of gross population and urbanization rate of municipalities in 2010.

\begin{tabular}{cccc}
\hline Municipality & $\begin{array}{c}\text { Gross resident population } \\
\text { (ten thousand) }\end{array}$ & $\begin{array}{c}\text { Non-agricultural resident population } \\
\text { (ten thousand) }\end{array}$ & Urbanization rate (\%) \\
\hline Beijing & 1961.90 & 1686.40 & 85.96 \\
Shanghai & 2302.66 & 2046.14 & 88.86 \\
Tianjin & 1299.29 & 1033.59 & 79.55 \\
Chongqing & 2884.62 & 1529.55 & 53.02 \\
\hline
\end{tabular}

Source: 2011 Statistical Yearbook of Municipalities and Sixth Census Data Bulletin in 2010. 
First, it does not match the development goals. Chongqing is a national central city, an important growth pole of the western China and an economic center in the upper reaches of Yangtze River. According to "314" overall deployment, the population urbanization level and quality of Chongqing are important measurement indexes for the achievement of the goal of a well-off society firstly in the western region. Seen from current development characteristics of Chongqing population urbanization, the progress of population urbanization of Chongqing still lags behind the demands of economic and social development; the population structure is irrational in two aspects, age and education level [6]. These development weaknesses do not match Chongqing's overall development objectives and will influence the progress of urbanization of Chongqing for a long time.

Second, it does not match the development pattern. The rapid achievement of Chongqing's urbanization means to increase the proportion of non-agricultural population, at the same time relocate the migrated agricultural population in cities and towns reasonably, thereby promote local economic development. Theoretically, adequate human resources and lower labor costs will contribute to the development of industry, which will lay a foundation for Chongqing undertaking industrial transfer and promoting industrial agglomeration. However, the non-agricultural population is large in Chongqing, so the migration duration will be long and the cost incurred will be high; as a result, it may delay the industrial layout and development opportunity. Secondly, population aging will cause the lack of actual labor and increase costs of social provision for the aged; at last, the lower quality of the population puts industrial development in the state of the lack of skilled workers and increases training costs of human resources. The shortage and lack of high-tech talent, innovative talent and strategic think tank will further affect industrial upgrading, the knowledge economy and knowledge-intensive industrial layout, the development of new high-tech and strategic industries in the intellectual resources and labor quality, which may hinder the transition of Chongqing development pattern, but also have a serious impact to further narrow the income gap between urban and rural areas [7]. The Government's financial investment in the equalization of public services and social security fairness will face great pressure.

\section{The Dilemma of Population Urbanization Development}

There are four main contradictions between population characteristics and urbanization development in Chongqing.

\subsection{The Contradiction between Large Population Base and Rapid Urbanization Goal}

According to the annual average urbanization growth rate of $1.6 \%-1.7 \%$ in Chongqing and the current population base, it is estimated that by 2020 the urbanization rate will reach $70 \%$ in Chongqing and more than 22 million people will become non-agricultural, and the new urban population will be about 6 million. According to new employee family dependents population $=$ new employment population $\times 50 \% \times 1.5$, the town will need to provide about 3.4 million jobs and the public services for people including about 2.6 million dependents. Large population urbanization brings great pressure for industrial clustering, governmental expenditure, public management, but also puts forward challenge for current population management system. In the process of urbanization, Chongqing should consider population management system reform, social management enhancement and other means to achieve the coordination between population urbanization goal and population base.

\subsection{The Conflicts between Population Aging and Relatively Lacking Labor}

In 2010, the population aging rate is $11.6 \%$ in Chongqing, which means there is one older at least among each 10 people in Chongqing. In consideration of adolescents, employee family dependants, the incapacitated and other factors, the actual population of labor in Chongqing is less than 12 million. It is expected that among these, the population of the persons who are capable for non-agricultural industries account for $70 \%$, about 8 million people. It needs adequate labor resources to accelerate industrial clustering, but there is some gap between limited labor force and labor demand. Despite the aging of population is not the main factor leading to a large gap in the labor force, but at least it brings partial constraints on the labor force supply. In addition, the aging of population also causes enormous pressure for old-age care undertaking to impact social consumption structure. Chongqing should consider the development of labor resource channels and the optimization of population structure, to effectively solve the labor shortage on the premise of that the governmental expenditure of old-age care and the population management difficulty are not increased [8] [9]. 


\subsection{The Conflicts between the Low Quality of Population and the Transition of Development Patterns}

The quality of the population is closely related with the level of education, and the quality of the labor force directly affects the speed and level of economic development. The data of "Six Popularizations" shows that the population of the people with college education or above is 2.493 million in Chongqing, the population of illiteracy is 1.239 million, accounting for $8.6 \%$ and $4.3 \%$ respectively, and the educated degree in Chongqing is medium in our country. The development of new urbanization requires the acceleration of industrial upgrading and the transformation of growth mode, and it requires great development of modern industry, modern service industry, knowledge-based economy and others, as well as the construction of knowledge city and intelligent city, all of which are inseparable from the participation of high-quality laborers and senior knowledge workers. Overall quality of workers determines their optimization in work skills and innovation ability. The educated degree of population in Chongqing is generally low, which is invisibly in conflicts with the further transition of development patterns and the improvement of knowledge-intensive degree in the long-term development process although it doesn't affect the current industrial development and labor supply. Chongqing should consider a new way to accelerate and improve population quality, and make the population quality meet the demand of industrial development and economic transformation in the premise of adequate labor force guaranteed.

\subsection{The Conflicts between "Entering City" and Local Integration of the Agricultural Population}

The ultimate goal of population urbanization is to improve the proportion of non-agricultural population. The agricultural population takes change in household register, which means the change of their residence, production and lifestyle. Regarding the direction and goals of population urbanization, it has two main choices: "entering city" and local integration. The former refers to entering the city, the latter refers to settling in the nearest small or medium city or small town. The "entering city" of agricultural population increased labor force for the city, bringing index of construction land and promoting urban consumption; but the urban collective consumption expenditure increased, the too large urban population caused various problems of ecology and management, and the city will suffer from the risk of "urban disease". While the local integration of agricultural population can relieve the pressure of the city from all aspects, reduce public service expenditure, make full use of surplus agricultural production capacity, and lay the foundation for improving agricultural production efficiency and large-scale production, but it has the disadvantages, e.g. more investment may be put into infrastructure construction of small and medium cities and small towns, more difficulties may be increased in ecological protection, the number of local jobs may hardly meet the employment needs of resettled population, large pressures maybe brought in the industrial introduction and economic development. Chongqing should consider reasonable diversion of non-agricultural population, simultaneously increasing urban and rural income and improving the quality of urban and rural life, and should give attention to the economic development, fiscal budget and expenditure, infrastructure construction, environment protection, public services and other problems in the process of population urbanization, to really achieve the wholly-planned urban and rural development.

\section{Strategies for the Development of Population Urbanization}

\subsection{Measures in the Population Urbanization and Population Management System}

Current population management system is the urban-and-rural dual household registration system, whose biggest shortcoming is the limit of population mobility and the generation of binary social service policies resulting in a binary life structure. Although the reform of the household registration system can alleviate this problem, it is not the only way. For example: in the Three Gorges reservoir area, the change of agricultural population household increase the proportion of non-agricultural population in a short time; the population urbanization rate increased rapidly, but there is huge pressure on the achievement of population citizenization, the acceleration of construction of cities and towns, the undertaking of industrial transfer and creation of jobs and ecological protection. The social welfare and public service for the migrated agricultural population are huge bottlenecks in local economic and social development. The reform of the household registration system is not to completely overturn the existing household registration management system. The government of Chongqing can explore the gradual liberalization of the household registration migration restrictions and realize the household changes 
conditionally, meanwhile, let the non-agricultural residents that are converted from agricultural household enjoy equitable social services to avoid excessive social management pressure, implement a flexible household and population management approach, change household management into local management and use tax, personal credit system and other leverages to effectively control irregular population migration and household change.

\subsection{Strategies in Labor Resources and Elderly-Care Policies}

Based on the current rate and characteristics of the population urbanization, the author estimates Chongqing's local labor resources can hardly meet local economic development in the future, so it is necessary to find out a variety of labor resource supply channels. Therefore, taking advantage of undertaking industrial opportunity and the full development and utilization of local agricultural labor resources have become the best choice. The government of Chongqing can adopt policies to encourage migrant workers back for employment, take appropriate preferential policies on the use of labor resources in the surrounding area. In order to alleviate the government's pressure to support the aged and reduce fiscal expenditure, it is suggested to actively explore public mode, social mode, community mode, family mode and other combined modes to support the aged. The government can support to develop the elderly-care industry, the elderly-care economy, improve investment environment, introduce appropriate incentives and develop the elderly-care undertakings [10].

\subsection{Strategies for the Development of Human Resource and the Benefit of Economy}

It is suggested to introduce policies to attract talent to Chongqing for study, employment, starting a business and settling down, encourage and support the development of universities and training institutions in Chongqing, improve social service capacity and training capacity, further popularize compulsory education, reduce illiterate and semiliterate population, encourage innovation, creativity, set up fund, bonuses and incentives to finance innovation in Chongqing, accelerate the conversion speed of production-education-research and develop investment and financing platform to promote the gathering and development of knowledge-intensive industries.

\subsection{Strategies for Surplus Agricultural Population Migration and Urban-Rural Development}

Based on the scientific planning of the urban systems and spatial layout, the accurate positioning of the urban functions and the reason allocation of industry, it is suggested to realize rational diversion of non-agricultural population and keep the population size in line with the carrying capacity of the city at all levels. It is also suggested to use the urban land effectively, eliminate the waste or dilapidation or hoard of land, lay stress on urban supporting functions and the quality and coordination degree of infrastructure construction, accelerate the construction of small towns, accelerate the development of township enterprises, attract urban capital investment in agriculture industries, encourage to manage modern agriculture through corporations, introduce appropriate taxation, loans, new financing approaches to develop agricultural economy, renovate and beautify "Villages in City", improve the level and quality of public services and achieve the urban-and-rural equalization of public services.

\section{Conclusion}

To sum up, China's current population management system is the urban-and-rural dual household registration system, whose biggest shortcoming is the limit of population mobility and the generation of binary social service policies resulting in a binary life structure. Although the reform of the household registration system can alleviate this problem, it is not the only way. If the government of Chongqing abrogates the household registration alteration restrictions, realizes the household changes conditionally, and let the non-agricultural residents that are changed from agricultural household enjoy equitable social services, excessive social management pressure can be avoided. For the implementation of a flexible household and population management approach, the government should change household management into local management and can use tax, personal credit system and other leverages to effectively control irregular population mobility and household alteration. In future, the government of Chongqing can take advantage of undertaking industrial opportunity, make full development and utilization of local agricultural labor resources, take policies to encourage migrant workers back for employment and attract surrounding labor resources, and actively explore various combination pension ways and develop the 
old-age undertakings. The government can plan the urban space layout in the scale of urban system to achieve diversion of non-agricultural population reasonably, speed up the construction of small towns and find a new road for Chongqing's urbanization in line with the actual situation.

\section{Project Funds}

Chongqing Social Science Planning Youth Project "A Strategic Study on Urbanization in Chengdu Economic Zone under the Background of Overall Urban and Rural Development" (2012QNSH019).

\section{References}

[1] The Task Team of Chinese Population and Development Research Center (2012) Strategic Research on Urbanization of China's Population. Study on Population, 36, 3-13.

[2] Lin, J. (2010) Analysis on Provincial Differences in Population Urbanization Level Change Since 2000. Study on Planning, 34, 48-56.

[3] Xu, Y.M. (2009) System Innovation from "Space Urbanization to the Population Urbanization". Reform, 182, 148150 .

[4] Qiu, B.X. (2011) Way of New Urbanization in China. Towns Construction in Guangxi, 2, 36-41.

[5] Li, K. and Yan, W. (2009) Exploration of Effective Way of "Space Urbanization" and "Population Urbanization". Reform, 182, 158-160.

[6] Xiang, W. (2011) Difficulties and Countermeasures for China's Population Urbanization. Macroeconomic Management, 10, 31-43.

[7] Wang, Q.M. (2009) The Key to the Coordination between "Space Urbanization" and "Population Urbanization" Depends on the Rural Urbanization. Reform, 182, 154.

[8] Chen, G.Q., Li, X. and Xu, X.Q. (2008) Spatial Clustering Characteristics of China's Urban Population and Its Rule Analysis. Geographical Journal, 63, 45-54.

[9] Chu, A.L. (2011) Some Thoughts on Accelerating the Development of New Urbanization Process. Agricultural Economy, 8, 8-10.

[10] Dong, W.P. (2009) Brief Discussion on Relative Issues of Agricultural Population Urbanization. Henan Agriculture, 2 , 55-56. 
Scientific Research Publishing (SCIRP) is one of the largest Open Access journal publishers. It is currently publishing more than 200 open access, online, peer-reviewed journals covering a wide range of academic disciplines. SCIRP serves the worldwide academic communities and contributes to the progress and application of science with its publication.

Other selected journals from SCIRP are listed as below. Submit your manuscript to us via either submit@scirp.org or Online Submission Portal.
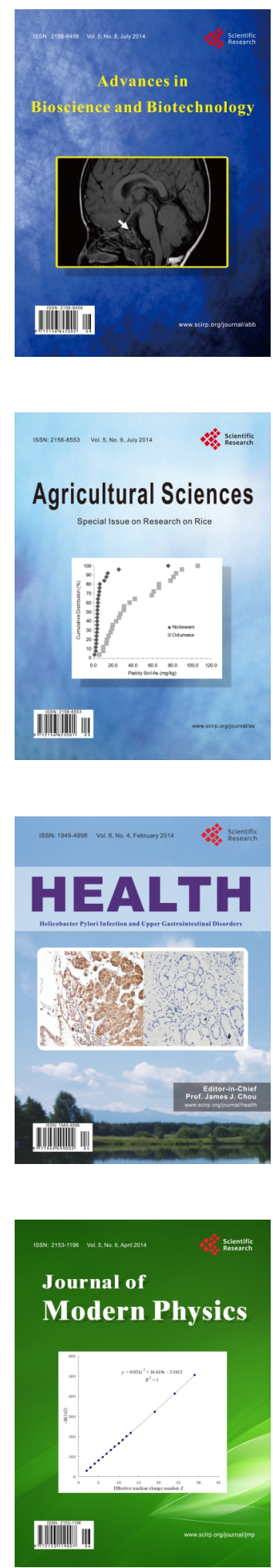
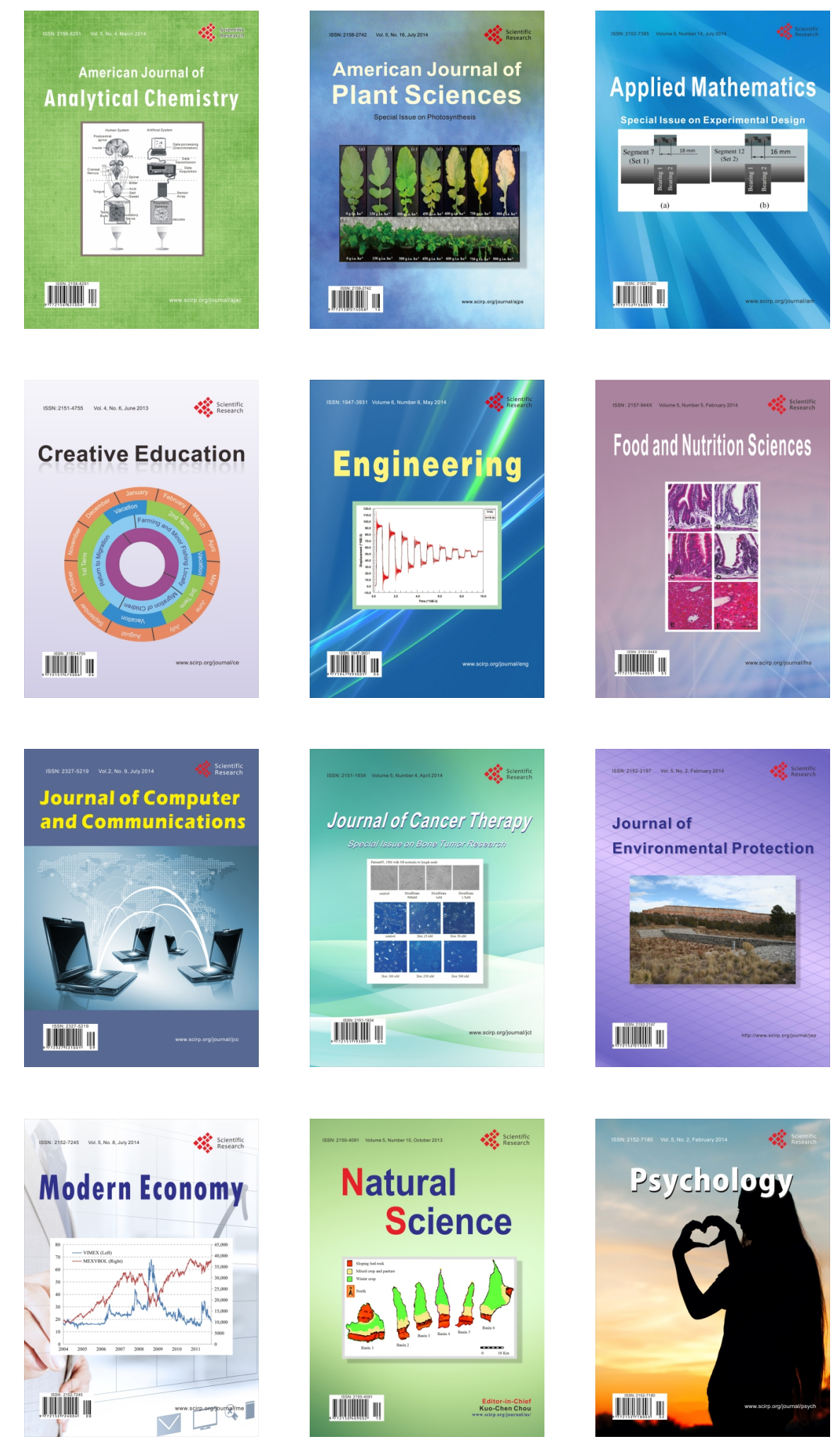